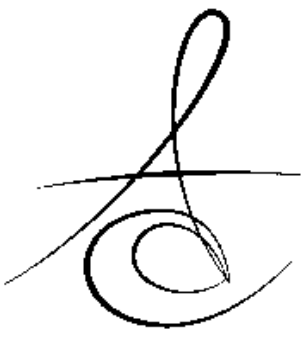

\section{PLEOMORFİK ADENOMASI BULUNAN ERKEK HASTANIN CERRAHİ TEDAVİSİ VE PROTETİK REHABİLITTASYONU: OLGU SUNUMU}

\section{THE SURGICAL TREATMENT AND PROSTHODONTIC REHABILITATION OF A MALE PATIENT WITH PLEOMORPHIC ADENOMA: A CASE REPORT}

\author{
Arş.Gör. Adnan Ege KÖSELER* \\ Yrd.Doç.Dr. Bahadır KAN**
}

Makale Kodu/Article code: 2374

Makale Gönderilme tarihi: 03.08.2015

Kabul Tarihi: 30.09.2015

\section{öz}

Pleomorfik adenom tükürük bezlerinin en sık görülen tümörüdür ve sıklıkla parotis bezinde yerleşim gösterir. Klinik olarak ağrısız, yavaş büyüyen şişlik bulgularına sahiptir. Histolojik olarak hem mezenkimal hem epitelyal dokuları içerir. Tedavide total eksizyon genellikle yeterli olsa da rekürrens görülme olasılığı yüksek bir tümör olduğundan takip gereklidir. Protetik yaklaşım olarak; retansiyon, stabilite ve estetiğin sağlandığı obtüratör protezler tercih edilebilmektedir. Defekt bölgesinde yumuşak astar materyali ile bitirilmesiyle hastanın daha rahat bir şekilde protez kullanımına adapte olması sağlanmaktadır. Bu çalış̧mada 56 yaşındaki erkek hastanın tedavisinde tercih edilen cerrahi ve protetik süreç anlatılmaktadır. Anahtar kelimeler: Pleomorfik adenom, yumuşak astar materyali, akrilik rezin

\section{ABSTRACT}

Pleomorphic adenomas are the most common neoplasms of salivary glands and are mostly localized in parotis gland. Clinically, patients present with a smooth painless enlarging mass. Histologically, they contain both mesenchymal and epithelial tissues. For the treatment most of time surgical excision is preferred, however as the tumour is poorly encapsulated, there is a significant rate of recurrence in the tumour bed so follow up is needed. At the prosthetic stage, in order to provide, function, retention and aesthetics; obturator prostheses can be used. For making it easier to adapt, we can reline the defect side of the prostheses with soft relining materials. In this case report, we present 56 years old male patient with pleomorphic adenoma and his multidisiplinary treatment protocol.

Key words: Pleomorphic adenoma, soft relining materials, acrylic resin

\section{GİRIş}

Pleomorfik adenoma tükürük bezlerinin etyolojisi bilinmeyen benign karakterli tümörüdür. ${ }^{(1,2)}$ Sıklıkla parotis ve submandibular bezlerde tutulum göstermektedir. Daha az da olsa sert damak ve diğer oral mukoza dokuları üzerinde bulunan minör tükürük bezlerinde de lokalize olabilirler. ${ }^{(3)}$ Minör tükürük beze yerleşimleri çok nadir görülen bu tömörler oral kavitede en çok sert ve yumuşak damakta görülürler. Tümörün sert damakta sıkça gelişmesinin nedeni, bu alandaki glandüler yapının bol olması ile açıklanmaktadı. ${ }^{(4)}$ Tümörün epitel kaynaklı olduğu biliniyorsa da, çok değişik hücresel yapılar gösterebildiği için mikst tümör terimi de kullanılmaktadır. Tümör makroskopik olarak düzensiz olabileceği gibi, oval şekilli, lobüler veya nodüler de olabilir. ${ }^{(5)}$ Pleomorfik adenoma sıklıkla ağrı yapmayan sıkı kitle olarak gözlenmekle birlikte onu çevreleyen mukoza üzerinde çoğunlukla ülserasyon oluşturmaz. Sert damakta lokalize olmadığı sürece genellikle hareketlidir. Bu tümörlerin \%25 kadarı malign dönüşüm gösterebilmektedir. Tedavileri, radikal cerrahi işlemler ile gerçekleştirilmektedir. Yetersiz rezeksiyon sıklıkla rekürrens ile sonuçlanmaktadır. ${ }^{(6)}$ Cerrahi olarak tedavi edilmediği takdirde büyük boyutlara ulaşabilen bir tümördür. ${ }^{(7)}$ Tüm yaşlarda görül- 
Atatürk Üniv. Diş Hek. Fak. Derg.

J Dent Fac Atatürk Uni

Supplement: 14, Yll: 2016, Sayfa : 50-55
KÖSELER, TOPÇU, KAN, SARIDAG mekle birlikte, en çok 4. ve 5. dekatlarda görülmektedir ve bayanlarda erkeklere oranla daha sıktır. ${ }^{(8)}$ Cerrahi sonrası oluşan defektlerin rehabilitasyonunda çoğu zaman obtüratör protezler başarıyla kullanılmaktadır. Defektlerin protez ile uyumlu bir ilişki içinde olabilmesi için sıklıkla yumuşak astar materyalleri tercih edilmektedir. Kullanılan astar materyallerinin, protez kaidesine kuvvetli bir bağlantı sağlaması ${ }^{(9)}$, boyutsal stabilitesini koruması ${ }^{(10)}$, reziliensin idamesi ${ }^{(11)}$, düşük su emilimi ${ }^{(12)}$, renk stabilitesi ${ }^{(13)}$ ve biyouyumluluk ${ }^{(14)}$ gibi özellikleri bulundurması tercih nedenidir. Fakat günümüzde kullanılan yumuşak astar materyallerinde; reziliens kaybı, su emilimi, Candida Albicans kolonizasyonu ve astarın protezden ayrılması gibi sorunlar ile de karşılaşılmaktadır. Bu yüzden sık klinik değerlendirme ve yumuşak astar materyalinin belli aralıklarla değiştirilmesi önerilmektedir. ${ }^{(15,16)} \mathrm{Bu}$ çalışmada anterior maksillada pleomorfik adenomu olan bir olgu sunulmuştur.

\section{OLGU SUNUMU}

56 yaşında erkek hasta, premaksillada 3 yıldır bulunan ve zamanla büyüyen ağrısız kitle şikayeti ile cerrahi kliniğine başvurdu(Resim 1). Hastanın, sigara ve alkol kullanma hikayesi olmasına rağmen sistemik hastalık ve daha önceden geçirilmiş bir operasyon hikayesi yoktu. Lenf nodu muayenesinde palpasyon bulgusuna rastlanmadı. İntraoral muayenede kitlenin karnıbahar görünümünde olup ekstraoral ekspansiyona yol açarak üst dudağın elevasyonuna sebep olduğu görüldü. Konik ışınlı bilgisayarlı tomografi bulgularında maksilla anteriorda bukkal ve palatinal kemik korteksinde ekspansiyona sebep olan radyolüsent lezyonun sınırları premaksiller segmentin destrüksiyonuna bağlı düzensiz olarak izlendi (Resim 2). İlgili bölgeden lokal anestezi altında insizyonel biyopsi alınarak patoloji konsültasyonu istendi ve histopatolojik inceleme sonucunda pleomorfik adenoma tanısına ulaşıldı. Hastanın genel anestezi altında opere edilmesine karar verildi. Rutin cerrahi hazırlığı takiben premolarlar arası bölgede sağlam doku sınırını da içerecek şekilde mukogingival katlantının en derin yerinden koterle insizyon yapıldı. Künt diseksiyonla premaksillayı kaplayan lezyon anteriordan başlanarak palatinale doğru rezeke edildi. Lezyonun tabanındaki kemik kürete edildi. Dudak ve yanaktaki sağlıklı yumuşak dokular 3.0 vikril süturla rezidüel palatinal kemiğe serum banyosu altında açılan deliklere tespit edildi (Resim 3). Primer kapatılamayan kemik, baktroban pomat emdirilmiş tampon ile kapatılarak süture edildi. Lezyon tümüyle patolojik incelemeye gönderildi. Postoperatif herhangi bir komplikasyon görülmedi. Histopatolojik inceleme sonucu preoperatif tanı ile uyumlu olarak pleomorfik adenom olarak rapor edildi. 3 ay sonra operasyon sahasının kontrolü için cerrahi sınırlardan tekrar biyopsi yapıldı. Patolojik bulguya rastlanmamasının ardından hasta rutin takip altına alındı. 2 senelik takip sürecinde herhangi bir patolojik bulgu gözlenmedi ve protetik tedaviye başlandı. Radyolojik ve klinik incelemenin sonrasında tanı modeli elde edilerek kapanış ve okluzyon değerlendirildi. İmplant destekli protez seçeneği, yetersiz kemik yapısı, ileri cerrahi işlemler gerektirmesi ve ekonomik nedenlerden dolayı uygulanmadı. Maksillada kalan sağ, sol birinci ve üçüncü molar dişlerin idamesine ve bu dişlerden destek alan hareketli obturatör protez yapımına karar verildi. Teşhis modelleri üzerinde kişisel kaşıklar hazırlandı. Tırnak yuvası ve tutucu unsurlar protezin uzun süreli idamesini sağlamak için maksimum sayıda planlandı. ${ }^{(14)}$ Kenar şekillendirmesi termoplastik stenç (Kerr impression compound, Scafati, Italy) ile yapıldı. Alt ve üst fonksiyonel ölçüler irreversible hidrokolloid (Cavex Cream, Haarlem, Holland) ölçü malzemesi ile alındı. İskelet provada ana bağlayıcı ve tırnakların oturumu kontrol edildi. Retansiyon; damak plağı ve molar dişlerin bukkal yüzeylerinde konumlandırılan çevresel kroşeler yardımıyla sağlandı. Dişli provada gülme hattı, dudak desteği, okluzyon, orta hat, renk uyumu kontrol edildi. Polimetilmetakrilat yapıdaki protezlerin, burun tabanına yakın olan bölgesi yumuşak astar materyali Molloplast-B (Dentax, Ettingen, Germany) ile bitirildi(Resim 4). Okluzyon ve kenar uyumlama işlemlerinin yapılmasının ardından protezler hastaya teslim edildi(Resim 5,6).

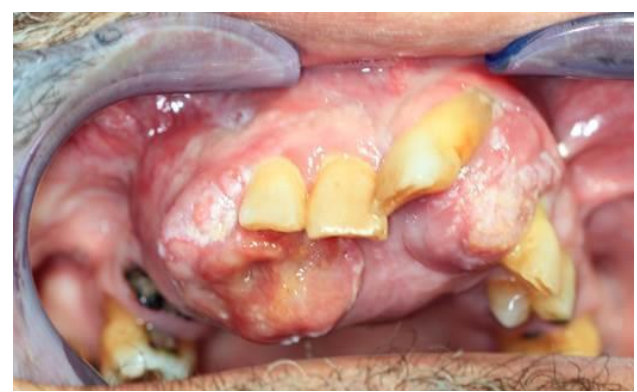

Resim 1.Kitlenin preoperatif ağız içi görünümü. 


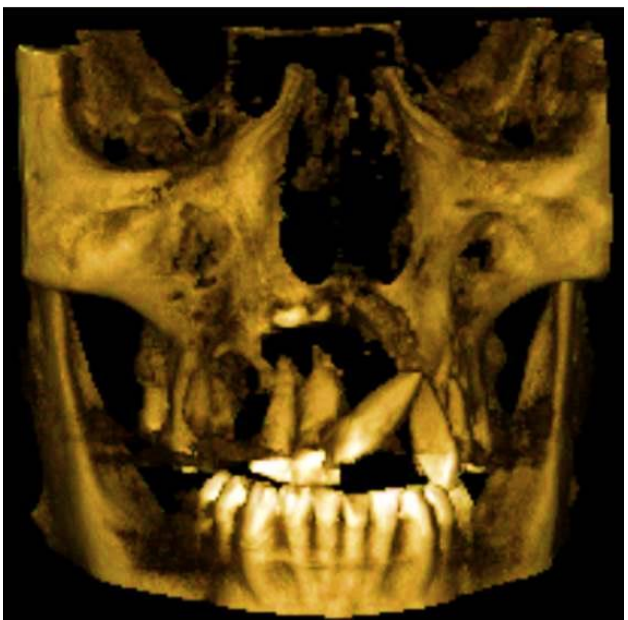

Resim 2.Bilgisayarlı tomografi ve premaksilladaki destrüksiyon.

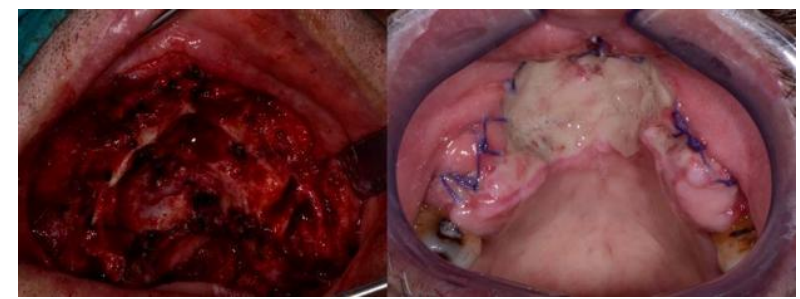

Resim 3.Lezyonun rezeksiyonu ve dokuların süture edilmesi.

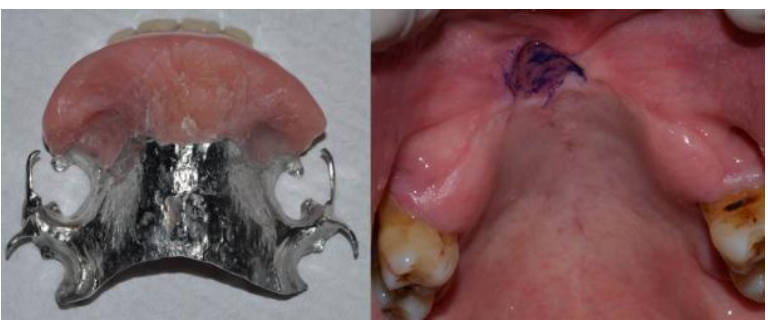

Resim 4. Polimetilmetakrilat yapıdaki protezin, burun tabanına yakın olan bölgesinin yumuşak astar materyali ile bitimi.

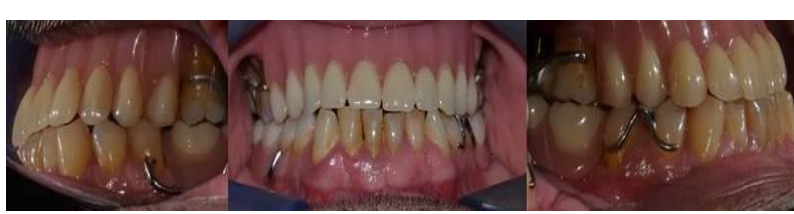

Resim 5.Okluzyon ve protezlerin ağız içi görünümü.

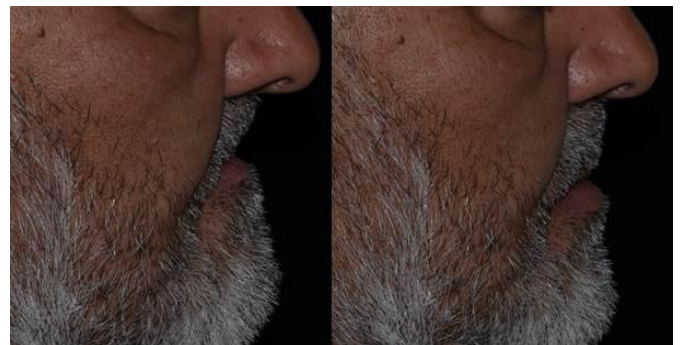

Resim 6. Protez öncesi ve sonrası doku ve dudak desteği.

\section{TARTIŞMA}

Pleomorfik adenom tükürük bezlerinin en sık karşılaşılan tümörüdür. ${ }^{17} \mathrm{Hem}$ epitelyal hem mezenkimal dönüşüm gösterebilen hücrelere sahiptir. ${ }^{2,18}$ Morfolojik olarak karmaşık yapılıdır çünkü tümör hücreleri fibrotik, hyalinize, osseoz, miksoid, kondroid alanlara metastaz yolu ile ya da tümör hücresi ürünü olarak dönüşebilmektedir. ${ }^{19}$ Parotis bezi yerleşimli olanların çoğu yüzeyel lobda tutulum göstermektedir ve klinik olarak kulak önünde ramusta şişlik ile kendini belli eder. Genellikle noduler sıkı düzensiz bir lezyondur. Fiksasyon göstermez. ${ }^{17}$ Fasiyel sinir tutulumu ve ağrı nadir görülür. Pleomorfik adenomların sadece $\% 10$ 'u fasial sinirin altından parotis bezinin derin lobuna yerleşir. Az sayıda tümör de, stilomandibular ligament ile ramus arasından medial yöne doğru büyür ve lateral faringeal duvar ya da yumuşak damakta kütle olarak kendini belli eder. ${ }^{20}$

Sıklıkla parotis ve submandibular bezde görülen bu lezyon, minör tükrük bezlerini de tutmaktadır. Olgu sunumunda da sert damak minör tükrük bezini tutan ve oldukça büyük boyutlara ulaşan nadir görülen bir vaka anlatılmıştır. Tokodo ve Suziki ${ }^{21}$ yaptığı araştırmada bu tümörü minör tükrük bezlerinde \% 10 oranında saptamışlardır. Araştırma sonucunda sert damakta yerleşen pleomorfik adenomların \%65, yanak mukozasında yerleşenlerin ise $\% 15$ oranında görüldükleri bulunmuştur.

Tümörün görüntülenmesi için manyetik rezonans görüntüleme (MRG) yada bilgisayarlı tomografi kullanılabilir. Yumuşak doku incelemesi için MRG daha iyi olsa da her 2 yöntemle de lezyon saptanabilir. Sunulan vakada lezyonun oldukça büyük bir alanı kapsadığı ve kemik dokuda destrüksiyon yarattığı panoramik radyografta görüldüğünden kemik dokuyla ilişkisinin ve sınırlarının net olarak belirlenebilmesi için

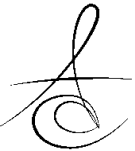


Atatürk Üniv. Diş Hek. Fak. Derg.

] Dent Fac Atatürk Uni

Supplement: 14, YIl: 2016, Sayfa : 50-55
KÖSELER, TOPÇU, KAN, SARIDAG
3 boyutlu dental volümetrik tomografiden yararlanılmıştır. Biyopsi alınırken ince iğne aspirasyon biyopsisi pek çok tükürük bezi tümöründe olduğu gibi tavsiye edilmektedir. ${ }^{22}$ Eksizyonel biyopsi rekürrens intimalinden ötürü önerilmemektedir. Lokal rekürrens çoğunlukla ilk tümörün enüklasyonu sonrası görülmektedir. Sunulan vakada lezyonun yapısı ve büyüklüğü göz önünde bulundurulduğunda insizyonel biyopsi ile lezyon tanısına ulaşılıp, operasyon planı histopatolojik inceleme sonucuna göre yapılmıştır. Pleomorfik adenomun sahip olduğu psödopodlar sayesinde rekürrense eğilimli olduğu bilinmektedir. Enüklasyon sonrası rekürrens oranı \%20-45 arasında değişmektedir. ${ }^{23}$

Tedavi için cerrahi eksizyon önerilmektedir. Rekürrens ve metastazı önlemek için submandibular bez yerleşimli tümörlerde bezin tamamının alınması söz konusu olabilmektedir. Parotis bezi yerleşimli olanlarda da parotisin yüzeyel lobunun alınması çoğu zaman gerekmektedir. ${ }^{24,25}$ Tedavi edilmeyen tümörler adenokarsinomaya ya da farklılaşmamış karsinomaya dönüşebilmektedir. Malign dönüşüm riski tümörün bulunma süresi ve hastanın yaşına bağlıdır. Rekürrens ya da malign dönüşümü gözlemlemek için uzun süreli takip bu hastalarda şarttır. ${ }^{26} 3$ yıldır rutin takipleri yapılan vakada rekürrens ve malign dönüşüm görülmemiştir.

Günümüzde sıklıkla kullanılan yumuşak astar malzemeleri akrilik ve silikon esaslı olmak üzere iki ana başlık altında toplanır. Büyük defekti bulunan hastalarda protez yapımı sırasında daha dayanıklı olan silikon esaslı astar malzemeleri tercih edilmektedir. Bu materyallerin çoğu zaman pöroziteler barındırmalarından ötürü Candida Albicans ve benzeri mantarlar için alan oluşturdukları rapor edilmiştir. Bu vakada ise protetik rehabilitasyon sırasında kullanılmış olan yumuşak astar materyali Molloplast-B'nin bazı silikon astar materyalinden farklı olarak Candida Albicans çoğalmasını inhibe edici özelliği bulunmaktadır. ${ }^{27,28}$ Astar materyallerinin viskoelastik özellikleri klinik kullanımdaki etkinliklerine katkı sağlar. Salloum ve ark. ${ }^{29}$ akrilik rezin ve silikon esaslı astar materyallerinin viskoelastik özelliklerini kıyasladıkları çalışmalarında, silikon astar materyali Molloplast-B'nin daha elastik olduğunu akrilik rezin esaslı Vertex Soft'un (Vertex Dental, Zeist, The Netherlands) ise vizköz özellikler gösterdiğini rapor etmiştir. Düşük vizkozite değerleri, yumuşak astar materyallerinin klinik kullanımda zarar görmüş dokulara uyum sağlamalarında gerekli bir özelliktir. Az akışkanlık gösteren silikon astar materyalleri bütünlüklerini daha uzun süre koruyabilmektedir. Öte yandan akrilik rezin esaslı astar materyallerinin vizkoelastisitelerinin ağız dokularına oldukça yakın olduğu bilinmektedir. ${ }^{(29)} \mathrm{Bu}$ durum onların önemli bir avantajı gibi görünsede uzun dönemde yapılarında bulundurdukları plastisizör ajanların tükürük ile teması sonucu çözülmeleri sonrası bu materyal vizkoelastik özelliklerini yitirmektedir. Akrilik rezin esaslı astar materyalleri sadece kısa süreli kullanımlarda önerilmektedir. ${ }^{\left({ }^{30}\right.}$ Uzun süreli kullanımda ise stres altında kendilerini toparlama yeteneği daha fazla olan silikon esaslı astar materyallerinin kullanımları önerilmektedir. ${ }^{29,30}$ Schmidt ve ark. ${ }^{31}$ Molloplast-B ile astarlanmış polimetilmetakrilat protez kullanan hastalarda yaptıkları 6 yıllık takip sonrası, hastaların \%93'ünün protezlerinden memnun kaldığını fakat $\% 95$ 'inin protezinin yenilenmesi gerektiğini rapor etmiştir.

Maksillofasiyel defektlerin rehabilitasyonunda multidisipliner bir çalışma yapmak operasyon öncesi retansiyon açısından önemli olan dokuların korunması içinde gerekmektedir. ${ }^{(32)}$ Minör defektlerin cerrahi olarak rekonstrüksiyonu mümkün olabilsede büyük defektlerde estetiğin ve fonksiyonun yeniden sağlanabilmesi için protez intiyacı ortaya çıkmaktadır. Özellikle bu vakada olduğu gibi premaksilladaki büyük defektlerin dudak desteğini ortadan kaldırmasıyla estetik rehabilitasyonun sağlanması güçleşmekte ve çoğunlukla obtüratör protezler ile başarılı tedavilere ulaşılabilmektedir. İmplant destekli protezler sıklıkla ilk olarak tercih edilseler de, anatomik engellerin olması, yetersiz kemik geniş̧liği ve yüksekliği, hastanın ekonomik durumu, cerrahi kontraendikasyonlar gibi pek çok sebeple birlikte günümüzde konvansiyonel bölümlü protezler silikon astar materyalleriyle birlikte kullanılabilmektedir. ${ }^{(33,34)}$ Silikon elastomerler bu tip protezler için en uygun tercih olmakla birlikte kısa ömürlü olmaları ve renklenmeye olan yatkınlıkları nedeniyle çeşitli sorunlar oluşturabilmektedirler. ${ }^{(35)}$ Buna karşın hastaların rapor edilen yüksek memnuniyet seviyeleri bu tip protezlerin tercih edilmelerinde önemli bir etkendir. Hareketli obturatör protezlerin kullanılmaları ve ilgili defekt bölgesinin üzerinin açık kalması özellikle rekürrens ihtimali yüksek olan tümörlerin erken tanısında kilit rol oynayabilmektedir. Cerrahi konstrüksiyonun teknik hassasiyeti ve komplikasyon oranının yüksek olması hasta memnuniyetini düşürmekle birlikte protetik rehabilitasyonun önemini arttırmaktadır. ${ }^{36}$

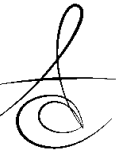


Atatürk Üniv. Diş Hek. Fak. Derg.

J Dent Fac Atatürk Uni

Supplement: 14, Yıl: 2016, Sayfa : 50-55
KÖSELER, TOPÇU, KAN, SARIDAG

\section{SONUÇLAR}

Defektli hastaların rehabilitasyonlarında multidisipliner yaklaşımlarda bulunmak, hastaların uzun süreli estetik ve fonksiyonlarının sağlanması için önemlidir. Obtüratör protezler ile hastanın rahat konuşabilmesi, beslenebilmesi, uygun bir estetik görünüme sahip olması ve psikolojik sorunlarında düzeltilmesi amaçlanır. Bu protezlerde defekt bölgelerinde kulanılan yumuşak astar materyallerinin zamanla özelliklerini yitirmelerinden ötürü konvansiyonel protezlere oranla daha sık aralıklarla takip gereklidir

\section{KAYNAKLAR}

1. Suen JY, Synderman NL. Benign neoplasms of the salivary glands. Otolaryngology-head and neck surgery.2.Ed. St.Louis:Mosby. 1993.p. 1029-42.

2. Bradley PJ. Pleomorphic salivary adenoma of the parotid gland: which operation to perform? Curr Opin Otolaryngol Head Neck Surg 2004;12:69-70.

3. Feinmesser R, Gay I. Pleomorphic adenoma of the hard palate: an invasive tumour? J Laryngol Otol 1983;97:1169-11.

4. Elder UK, Kline SN, Fader M. Mixed tumors of die palate: a statistical survey and report of two cases. Oral Sttrg Oral Med Oral Pathol 1961;14:257-269.

5. Lucas, RB. Pathology of Tumours of The Oral Tissues. 3. Ed. Edinburgh. London and New York. Churchill Livingstone. 1976. p. 299-310.

6. Clauser L, Mandrioli S, Dallera V, Sarti E, Galiè M, Cavazzini L. Pleomorphic adenoma of the palate. J Craniofac Surg 2004;15:1026-9.

7. Speight PM, Barrett AW. Salivary gland tumours. Oral Dis 2002;8:229-40.

8. Wang D, Li Y, He H, Liu L, Wu L, He Z. Intraoral minor salivary gland tumors in a chinese population: A retrospective study on 737 cases. Oral Surg Oral Med Oral Pathol Oral Radiol Endod 2007;104:94-100

9. McCabe JF, Carrick TE, Kamohara H. Adhesive bond strength and compliance for denture soft lining materials. Biomater 2002;23:1347-52.

10. Murata H, Taguchi N, Hamada T, Kawarmura M, McCabe JF. Dynamic viscoelasticity of soft liners and masticatory function. J Dent Res 2002;23:1238.
11. Dootz ER, Koran A, Craig RG. Physical property comparison of 11 soft denture lining materials as a function of accelerated aging. J Prosthet Dent 1993;69:114-9.

12. Gjengedal $H$, Berg $E$, Gronningsaeter AG, Dahl L, Malde $M K$, Boe OE. The influence of relining or implant retaining existing mandibular dentures on health-related quality of life: a 2-year randomized study of dissatisfied edentulous patients. Int J Prosthodont 2013;26:68-78.

13. Ergun G, Nagas IC. Color stability of silicone or acrylic denture liners: an in vitro investigation. Eur J Dent 2007;1:144-51.

14. McCabe JF. Soft lining materials: Composition and structure. J Oral Rehabil 1976;3:273-8.

15. Hashem MI. Advances in soft denture liners. JCDP 2015;16:314-318.

16. Mantri S, Khan Z. Prosthodontic rehabilitation of acquired maxillofacial defects. InTech 2012;31536.

17. Rajendran S, Sivapathasundaram S. Shafer's Textbook of Oral Pathology. Elsevier 2009;6:21924.

18. Neville BW, Damm DD, Allen CM, Bouquot JE. Oral \& Maxillofacial Pathology Elsevier 2009;3:477-479.

19. Friedrich RE, Li L, Knop J, Giese M, Schmelzle R. Pleomorphic adenoma of the salivary glands: analysis of 94 patients. Anticancer Res 2005; 25:1703-5.

20. Colella G, Cannavale R, Chiodini P. Meta-analysis of surgical approaches to the treatment of parotid pleomorphic adenomas and recurrence rates. J Craniomaxillofac Surg 2015;43:738-45.

21. Tokada Y, Suziki A. Benign pleomorphic adenoma arising in a parotid lymph node. Wirchows Arch Path Anat 1982;396:51.

22. Giurana RJ, Rodado C, Saez M, Bassas C. Giant parotid pleomorphic adenoma involving the parapharyngeal space: report of a case. J Oral Maxillofac Surg 2000;58:1184-7.

23. Oh YS, Eisele DW. Salivary Glands Neoplasms. Em: Bailey BJ, Johnson JT, Newlands SD. Head \& Neck Surgery - Otolaryngology. 4th ed. Philadelphia: Lippincott Williams \& Wilkins. 2006. pp. 1516-33.

24. Batsakis JG, Sneige N. Pathology consultation: parapharyngeal and retropharyngeal space diseases. Ann Otol Rhinol Laryngol 1989;98:320-1.

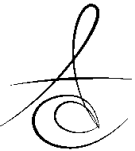


25. Hugues KV, Olsen KD, MacCafferey TV. Parapharyngeal space neoplasms. Head Neck 1995;17:124-30.

26. Feinmersser R, Gay I. Pleomorphic adenoma of the hard palate an invasive tumor. J Laryngol Otol 1983;97:1169-71.

27. Atay A, Saraçlı M, Akyıl Ş, Tukay A, Oruç S. Candida Albicans'in Yumuşak Astar Maddelerine Olan Adezyonunun Modifiye Bir Teknikle İn-vitro Değerlendirilmesi. Hacettepe Diş Hek Fak Derg 2007; 31:74-8.

28. Karakış D, Akay C, Erdönmez D, Doğan A. Farklı yumuşak astar materyallerinin Candida albicans biyofilm formasyonu açısından değerlendirilmesi. Acta Odontol Turc 2015;32:19-25.

29. Salloum AM. Creep and stress relaxation behavior of two soft denture liners. J Indian Prosthodont Soc 2014;14:93-97.

30. Barsby MJ, Braden MA. Hydrophilic denture base resin. J Dent Res 1979;58(6):1581-1584.

31. Schmidt WF, Smith DE. A six-year retrospective study of Molloplast-B-lined dentures. Part 1:Patient response. J Prosthet Dent 1983;50(3):308-313.

32. Yaluğ S. Çene yüz bölgesinde cerrahi işlem sonrası görülen anatomi . Atatürk Üniv Diş Hek Fak Derg 1998;8:105-9.

33. Leonardi A, Buonaccorsi S, Pellacchia V, Moricca LM, Indrizzi E, Fini G. Maxillofacial prosthetic rehabilitation using extraoral implants. J Craniofac Surg 2008;19:398-405

34. Van der Lei B, Dhar BK, Van Oort RP, Robinson PH. Nasal reconstruction with an expanded forehead flap after oncological ablation: Results, complications and a review of the English language literature. FACE 1996;3:139-46.

35. Atay A, Günay Y. Çene-yüz protezlerinde bakım . Atatürk Üniv Diş Hek Fak Derg 2007;2:22-5.

36. Ariani N, Visser $A$, van Oort RP, Kusdhany L, Rahardjo TB, Krom BP, van der Mei HC, Vissink A. Current state of craniofacial prosthetic rehabilitation. Int J Prosthodont 2013;26:57-67.

\author{
Yazışma Adresi \\ Yrd.Doç.Dr. Serkan SARIDAĞ \\ Kocaeli Üniversitesi Yuvacık Yerleșkesi \\ Diş Hekimliği Fakültesi \\ Protetik Diş Tedavisi A.D. \\ Başiskele/KOCAELİ, TÜRKİYE \\ e-mail: ssaridag@hotmail.com
}

